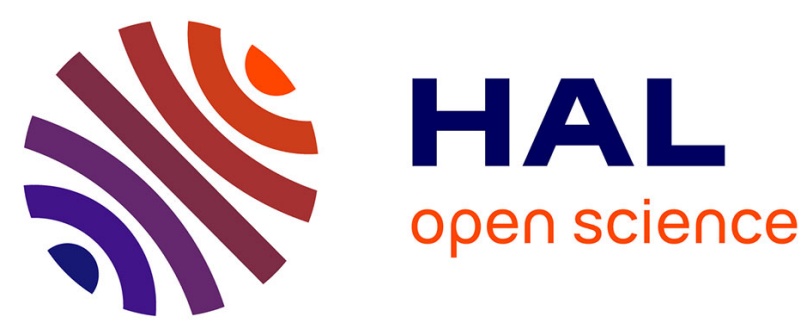

\title{
A new process for species separation in a binary mixture using mixed convection
}

Ali Khouzam, Marie-Catherine Charrier-Mojtabi, Abdelkader Mojtabi, Bafétigué Ouattara

\section{- To cite this version:}

Ali Khouzam, Marie-Catherine Charrier-Mojtabi, Abdelkader Mojtabi, Bafétigué Ouattara. A new process for species separation in a binary mixture using mixed convection. Advances in Computational Heat Transfer, CHT-12, Jul 2012, Bath, United Kingdom. hal-00967485

\section{HAL Id: hal-00967485 \\ https://hal.science/hal-00967485}

Submitted on 28 Mar 2014

HAL is a multi-disciplinary open access archive for the deposit and dissemination of scientific research documents, whether they are published or not. The documents may come from teaching and research institutions in France or abroad, or from public or private research centers.
L'archive ouverte pluridisciplinaire HAL, est destinée au dépôt et à la diffusion de documents scientifiques de niveau recherche, publiés ou non, émanant des établissements d'enseignement et de recherche français ou étrangers, des laboratoires publics ou privés. 


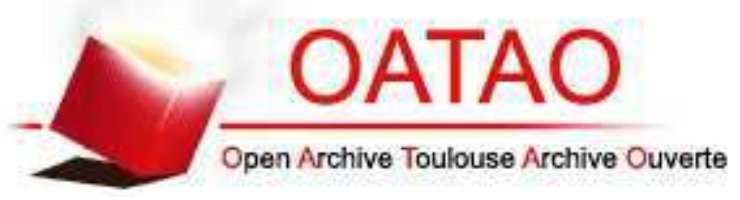

\section{Open Archive TOULOUSE Archive Ouverte (OATAO)}

OATAO is an open access repository that collects the work of Toulouse researchers and makes it freely available over the web where possible.

This is an author-deposited version published in : http://oatao.univ-toulouse.fr/ Eprints ID : 9789

To cite this version : Khouzam, Ali and Charrier-Mojtabi, MarieCatherine and Mojtabi, Abdelkader and Ouattara, Bafétigué A new process for species separation in a binary mixture using mixed convection. (2012) In: Advances in Computational Heat Transfer, CHT-12, 01 July 2012 - 06 July 2012 (Bath, United Kingdom).

Any correspondance concerning this service should be sent to the repository administrator: staff-oatao@ listes-diff.inp-toulouse.fr 


\title{
A NEW PROCESS FOR SPECIES SEPARATION IN A BINARY MIXTURE USING MIXED CONVECTION
}

\author{
Khouzam Ali ${ }^{*}$, , Marie Catherine Charrier Mojtabi ${ }^{* *}$, Abdelkader Mojtabi ${ }^{*}$ and Ouattara Bafétigué \\ * IMFT, UMR CNRS/INP/UPS N5502, UFR MIG, Université Paul Sabatier, 118 route de Narbonne, \\ 31062, Toulouse cedex, France \\ ** PHASE, EA 3028, UFR PCA, Université Paul Sabatier, 118 route de Narbonne, 31062, Toulouse \\ cedex, France \\ ${ }^{\S}$ Correspondence author. Fax: +33534322899, Email: akhouzam@imft.fr
}

\begin{abstract}
In this paper, a numerical and analytical analysis is performed in order to improve the species separation process in a binary fluid mixture by decoupling the thermal gradient from the convective velocity. The configuration considered is a horizontal rectangular cavity, of large aspect ratio, filled with a binary fluid. A constant tangential velocity is applied to the upper horizontal wall. The two horizontal impermeable walls are maintained at different and uniform temperatures $\mathrm{T}_{1}$ and $\mathrm{T}_{2}$ with $\Delta T=T_{1}-T_{2}$. Species separation is governed by two control parameters, the temperature difference $\Delta T$ and the velocity of the upper plate $\overrightarrow{U e_{\mathrm{x}}}$. The intensity of the thermodiffusion is controlled by the temperature, while the velocity $\overrightarrow{\mathrm{Ue}_{\mathrm{x}}}$ controls the convective flow. This problem depends on six dimensionless parameters, namely, the separation ratio, $\psi$, the Lewis number, Le, the Prandlt number Pr, the aspect ratio of the cell, A and two control parameters: the thermal Rayleigh number, Ra and the Péclet number Pe. In this study, the formulation of the separation (mass fraction difference between the two ends of the cell) as a function of the Péclet number and the Rayleigh number is obtained analytically. For a cell heated from below, the optimal separation $\mathrm{m}=\frac{\sqrt{42}}{15}$ is obtained for $P e=\frac{\sqrt{42}}{L e}$ and $R a=\frac{540}{L e \psi} .2 \mathrm{D}$ numerical results, obtained by solving the full governing equations, are in good agreement with the analytical results based on a parallel flow approach.
\end{abstract}

\section{INTRODUCTION}

A temperature gradient applied to a binary fluid mixture induces a mass fraction gradient: this phenomenon called thermodiffusion is also known as Ludwig-Soret effect or the Soret effect. Under the gravity field, the coupling between convection and thermodiffusion, namely thermogravitational diffusion may lead to species separation.

Clusius and Dickel (1938) successfully carried out the separation of gas mixtures in a vertical cavity heated from the side usually called thermogravitational column (TGC). The authors observed a significant separation of the gas components and suggested that this technique could be used for isotope separation. Furry et al. (1939) developed a fundamental theory to interpret the experimental 
process of isotope separation in TGC columns (FJO theory). However, in their study, the authors did not take into account the influence of the concentration gradient on the density gradient, which is referred as "forgotten effect". Afterwards, many works were devoted to justify and extend the results of the FJO theory to the case of binary liquids. Other studies were carried out in order to improve the experimental devices and increase the separation. Lorenz and Emery(1959) introduced a porous medium in the TGC columns. Bou-Ali et al. (1999) imposed, in a thermogravitational column, a horizontal temperature gradient to a binary fluid with a negative Soret coefficient. The authors observed a steady-state adverse density gradient along the layer and analysed the stability of this configuration. Three-dimensional numerical study of Soret-driven convection in a cubic cell filled with a binary mixture of water $(90 \%)$ and isopropanol (10\%) was performed by Shevtsova et al. (2006). The instabilities occurring in this binary fluid with negative Soret coefficient for a cubic cell heated from above was analysed.

In order to increase the separation, Platten et al. (2003) used an inclined cavity heated from the top. Elhajjar et al. (2006) suggested a new method to obtain species separation in a binary fluid mixture. The authors considered a horizontal parallelipipedic cavity subjected to a constant horizontal temperature gradient on the two horizontal walls to improve the separation process depending on two control parameters. They obtained significant separation $(10 \%)$ with realistic values of the thickness (about $2 \mathrm{~mm}$ ), while very low thicknesses $(0.2 \mathrm{~mm})$ were required in vertical cells to obtain separation with the same order of magnitude. Charrier-Mojtabi et al.(2008) developed a linear stability analysis of the unicellular flow which appears at the onset of convection in a horizontal porous cavity saturated by a binary fluid and heated from below. The authors showed that if the separation ratio $\psi$ is positive and greater than a particular value, $\psi_{\text {mono }}$, it is possible to separate the species of the binary fluid mixture between the two ends of the cell. Elhajjar et al. (2008) showed that the Rayleigh number leading to the optimum separation in a horizontal cell is larger than the one obtained in a vertical cell (TGC), which allows to perform separation in a cell of greater thickness. The existence of multiple solutions and the influence of the Soret effect on the convection in a horizontal porous layer under cross temperature and concentration gradients were discussed by Bennacer et al. (2009). Zebib and Bou-Ali (2009) performed a linear stability analysis of a binary mixture buoyant return flow in a tilted differentially heated infinite layer using asymptotic long-wave analysis and pseudo-spectral Chebyshev numerical solutions. Elhajjar et al.(2009) studied the influence of vertical high frequency and small-amplitude vibrations on the stability of the unicellular flow in a shallow horizontal porous layer saturated by a binary fluid and heated from below. Alloui et al.(2009) used the Darcy model with the Boussinesq approximation to study natural convection in a porous medium saturated by a binary fluid. It was found that both unicellular and bicellular symmetrical circulations are possible for centrally located heated element. Elhajjar et al. (2010) presented a theoretical and numerical study of species separation in an inclined porous cavity.

In this paper a study of the species separation in a binary fluid mixture is presented for a new geometrical configuration. The binary fluid mixture is confined in a shallow horizontal rectangular cavity heated either from above or below. The two horizontal impermeable walls are maintained at uniform temperatures $T_{1}$ and $T_{2}$. The upper horizontal wall moves with a constant velocity, $\overrightarrow{\mathrm{e}_{\mathrm{x}}}$. The dimensionless corresponding parameters of the problem studied are the Péclet number, Pe and the Rayleigh number, Ra. In addition to these two parameters, the problem depends on the separation ratio, $\Psi$, the Lewis number, Le, the Prandlt number, Pr and the aspect ratio of the cell, A. In order to obtain an analytical solution of the unicellular flow, occurring for a wide range of variation of the dimensionless parameters, the assumption of parallel flow is adopted. The velocity profile, the temperature and the mass fraction field are obtained using Maple software. The species separation is thus calculated as a function of Ra, Pe, Le, $\Psi$ and A.

For a cell heated from below the values of the Péclet number and the Raleigh number for which the separation is optimal are determined analytically. The analytical results are corroborated by direct 2D numerical simulations. 


\section{MATHEMATICAL FORMULATION}

Conservation equations An horizontal rectangular cavity filled with a binary fluid mixture submitted to vertical temperature gradient is considered. The dimensions of the cell are $\mathrm{H}$ along the $\mathrm{z}$-axis and $\mathrm{L}$ along the $\mathrm{x}$-axis. The aspect ratio of the cell $\mathrm{A}=\mathrm{L} / \mathrm{H}$ is larger than unity. The top and bottom walls of the cell are maintained, respectively, at temperatures $T_{1}$ and $T_{2}$ with $T_{1}>T_{2}$ or $T_{1}<T_{2}$. The lateral walls are assumed thermally insulated (see Figure 1). The binary mixture is considered as Newtonian fluid and the Boussinesq approximation is assumed valid. Thus, the thermo-physical properties of the fluid mixture are constant except the density in the buoyancy term, which varies linearly with the local temperature $T$ and the local mass fraction of the denser component $C$ :

$$
\rho=\rho_{0}\left[1-\beta_{T}\left(T-T_{0}\right)-\beta_{C}\left(C-C_{0}\right)\right]
$$

where the subscript 0 refers to the reference values of $\mathrm{T}$ and $\mathrm{C}$ (In this paper we consider $\mathrm{T}_{0}=\mathrm{T}_{1}$ ). $\beta_{T}$ and $\beta_{C}$ are, respectively, the thermal and the mass expansion coefficients defined as follows:

$$
\beta_{T}=-\frac{1}{\rho_{0}}\left(\frac{\partial \rho}{\partial T}\right)_{C}>0, \beta_{C}=-\frac{1}{\rho_{0}}\left(\frac{\partial \rho}{\partial C}\right)_{T}<0
$$

The heat and the mass fraction flux in the binary mixture are coupled due to the Soret effect and both contribute to the density gradient. The buoyancy force $\rho \vec{g}\left(\vec{g}=-g \overrightarrow{e_{z}}\right)$ is thus influenced by the Soret effect. Under these conditions, the mathematical model governing this problem, which includes the conservation equations (mass, momentum, energy and chemical species), is written as follows:

$$
\begin{gathered}
\nabla \cdot \vec{V}^{*}=0 \\
\rho_{0}^{*}\left(\frac{\partial \vec{V}^{*}}{\partial t^{*}}+\left(\vec{V}^{*} \cdot \nabla\right) \vec{V}^{*}\right)=-\nabla P^{*}+\rho_{0}^{*}\left[1-\beta_{T}\left(T^{*}-T_{0}^{*}\right)-\beta_{C}\left(C^{*}-C_{0}^{*}\right)\right] \vec{g}+\mu \nabla^{2} \vec{V}^{*} \\
\frac{\partial T^{*}}{\partial t^{*}}+\vec{V}^{*} \cdot \nabla T^{*}=a \nabla^{2} T^{*} \\
\frac{\partial C^{*}}{\partial t^{*}}+\vec{V}^{*} \cdot \nabla C^{*}=D \nabla^{2} C^{*}+D_{T} C^{*}\left(1-C^{*}\right) \nabla^{2} T^{*}
\end{gathered}
$$
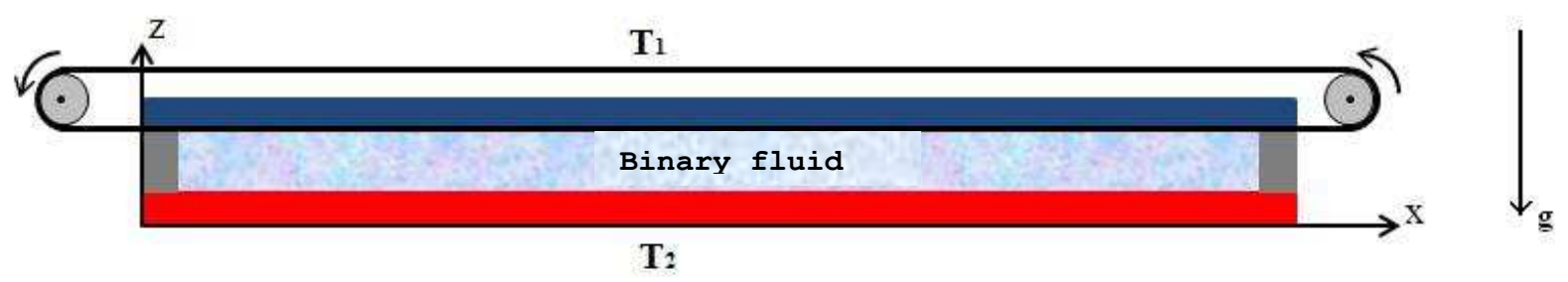

Figure 1. Geometry of the physical problem.

Where $D$, and $D_{T}$ are, respectively, the mass diffusion and the thermal diffusion coefficients, $\mu$ and $a$ are, respectively, the dynamic viscosity and thermal diffusivity of the binary fluid. In equations (2) to (5), the asterisks represent the dimensional variables, and the Soret coefficient is defined as: $S_{T}=\frac{D_{T}}{D}$ 
Typically, in the Soret-driven convection, if the mass fraction difference is small, $C^{*}\left(1-C^{*}\right)$ can be replaced by $C_{0}^{*}\left(1-C_{0}^{*}\right) C_{0}$ being the concentration in the initial state.

Boundary Conditions The associated boundary conditions include a constant velocity applied on the upper wall, no-slip condition for the velocity of the others rigid walls, distinct constant temperatures on the top and the bottom wall. Vertical walls are impermeable and thermally insulated. Accordingly, the associated boundary conditions are defined as follows:

$$
\begin{aligned}
& \left\{\begin{array}{l}
\vec{V}^{*}\left(x^{*}, z^{*}=H\right)=U \overrightarrow{e_{x}} \\
\vec{V}^{*}\left(x^{*}, z^{*}=0\right)=0
\end{array} \quad \forall \quad x^{*} \in[0, L]\right. \\
& \left\{\begin{array}{l}
T^{*}\left(z^{*}=H, x^{*}\right)=T_{1} \\
T^{*}\left(z^{*}=0, x^{*}\right)=T_{2}
\end{array}\right. \\
& \frac{\partial \mathrm{T}^{*}}{\partial \mathrm{x}^{*}}=\frac{\partial \mathrm{C}^{*}}{\partial \mathrm{x}^{*}}=0, \overrightarrow{\mathrm{V}}=\overrightarrow{0} \text { for } \quad \mathrm{x}^{*}=0, \mathrm{~L} \\
& \left(\mathrm{DVC} \mathrm{C}^{*}+\mathrm{D}_{\mathrm{T}} \mathrm{C}_{0}^{*}\left(1-\mathrm{C}_{0}^{*}\right) \nabla \mathrm{T}^{*}\right) \cdot \overrightarrow{\mathrm{n}}=0 \text { for } \mathrm{z}^{*}=0, \mathrm{H}
\end{aligned}
$$

Dimensionless Equations The references scales are: $H$ for the length, $\frac{H^{2}}{a}$ for the time, $\rho_{0} \frac{a^{2}}{H^{2}}$ for the pressure, and $\frac{a}{H}$ for the velocity. The dimensionless temperature and concentration are given by: $T=\frac{T^{*}-T_{1}}{\Delta T}, C=\frac{C^{*}-C_{0}^{*}}{\Delta C}$ where $\Delta T=T_{2}-T_{1}$ and $\Delta \mathrm{C}=\Delta \mathrm{TC}_{0}^{*}\left(1-\mathrm{C}_{0}^{*}\right) \frac{\mathrm{D}_{\mathrm{T}}}{\mathrm{D}}$.

Thus the dimensionless governing equations are given by:

$$
\begin{gathered}
\nabla \cdot \vec{V}=0 \\
\frac{\partial \vec{V}}{\partial t}+\vec{V} \cdot \nabla \vec{V}=-\nabla P+\operatorname{Ra} \operatorname{Pr}(T-\psi C) \vec{e}_{z}+\operatorname{Pr} \nabla^{2} \vec{V} \\
\frac{\partial T}{\partial t}+\vec{V} \cdot \nabla T=\nabla^{2} T \\
\frac{\partial C}{\partial t}+\vec{V} \cdot \nabla C=\frac{1}{L e}\left(\nabla^{2} C+\nabla^{2} T\right)
\end{gathered}
$$

Where $\psi=-\frac{\beta_{c}}{\beta_{T}} \frac{D_{T}}{D} C_{0}^{*}\left(1-C_{0}^{*}\right)$ is the separation ratio, and $\overrightarrow{\mathrm{e}_{\mathrm{z}}}$ is the unit vector along the z-axis.

The problem considered depends on six dimensionless parameters which are :

The Rayleigh number, $R a=\frac{g H^{3} \beta_{T} \Delta T}{v a}$, the Prandtl number, $\operatorname{Pr}=\frac{v}{a}$, the Lewis number, $L e=\frac{a}{D}$, the Péclet number, $P e=\operatorname{Pr} \operatorname{Re}$, where $\operatorname{Re}=\frac{U L}{v}$ (Reynolds number), the separation ratio $\psi$ and the aspect ratio $A=\frac{L}{H}$. 
In this paper, we consider $R a>0$ if the cell is heated from below, and $R a<0$ if the cell is heated from above. Moreover, a positive separation ratio is considered, which implies that, due to thermodiffusion, the denser component of the mixture migrates towards the cold wall.

The associated boundary conditions in dimensionless form are:

$$
\begin{gathered}
\vec{V}(x, z=1)=P e \overrightarrow{e_{x}}, \quad \vec{V}(x, z=0)=0 \\
T(x, z=0)=1 \quad ; \quad T(x, z=1)=0 \\
\frac{\partial T}{\partial x}=\frac{\partial C}{\partial x}=0, \vec{V}=\overrightarrow{0} \quad \text { for } x=0, A \\
\frac{\partial T}{\partial z}=-\frac{\partial C}{\partial z} ; \quad \text { for } z=0,1
\end{gathered}
$$

\section{ANALYTICAL SOLUTION}

In the case of a shallow cavity (A $>1)$, in order to solve the problem analytically, the parallel flow approximation (Bennacer et al.(2003), Elhajjar et al. (2010)) is considered. The streamlines are assumed to be parallel to the horizontal walls. In this case, the vertical component of velocity can be neglected:

$$
\vec{V}=u(z) \vec{e}_{x}
$$

This assumption implies steady-state and neglecting the inertia term $(\vec{V} . \nabla) \vec{V}$ in eq.(11).

The temperature and the mass fraction are written as follows:

$$
\begin{aligned}
& T(x, z)=b x+f(z) \\
& C(x, z)=m x+g(z)
\end{aligned}
$$

Where $\mathrm{b}$ and $\mathrm{m}$ are respectively an unknown constant temperature and mass fraction gradient, in the $\mathrm{x}$ direction. $b=0$, due to the constant temperatures imposed on the horizontal walls.

Using the equations (18) to (20), and after replacing the pressure in the Navier-Stokes equation (Eq.(11)), the following system of equations is obtained for the steady state:

$$
\begin{gathered}
\frac{\partial^{3} u(z)}{\partial z^{3}}-R a \frac{\partial}{\partial x}(T-\psi C)=0 \\
\nabla^{2} T=0 \\
m \operatorname{Leu}(z)-\frac{\partial^{2} C}{\partial z^{2}}=0
\end{gathered}
$$

Since the boundary conditions on vertical walls are not taken into account, additional conditions are needed to solve the system of equations (21)-(23) which are:

- The mass flow rate through any cross section perpendicular to the $\mathrm{x}$-axis is equal to zero,

- The mass conservation of the component of mass fraction $\mathrm{C}$ across the all cell,

$$
\int_{0}^{1} u d z=0 \quad \forall x \in[0, A], \quad \int_{0}^{1} \int_{0}^{A} C d z d x=0
$$

Applying these latter conditions and the boundary conditions (14) to (17) and using Maple software, the velocity, temperature and mass fraction fields are given by the following expressions: 


$$
\begin{gathered}
u=\left(-\frac{1}{6} z^{3}+\frac{1}{4} z^{2}-\frac{1}{12} z\right) \operatorname{Ra} \psi m+\left(3 z^{2}-2 z\right) P e \\
T=1-z \\
\mathrm{C}=\mathrm{mx}-\left(\frac{1}{120} \mathrm{z}^{5}-\frac{1}{48} \mathrm{z}^{4}+\frac{1}{72} \mathrm{z}^{3}+\frac{1}{1440}\right) \operatorname{Ra} \psi L \mathrm{Le}^{2} \mathrm{~m}^{2}+\mathrm{z}-\frac{1+\mathrm{mA}}{2}+ \\
\left.\left(\frac{1}{4} \mathrm{z}^{4}-\frac{1}{3} \mathrm{z}^{3}+\frac{1}{30}\right)\right) \mathrm{mLePe}
\end{gathered}
$$

The velocity has a cubic profile, which is required to allow specie separation between the two ends of the cell.

Determination of the mass fraction gradient $\mathbf{m}$ along the $\mathbf{x}$ axis To determine the mass fraction gradient, $m$, along the $\mathrm{x}$ axis, we use the fact that the mass flow rate of the species of mass fraction $\mathrm{C}$ through any vertical section is equal zero:

$$
\int_{0}^{1}\left(u C-\frac{1}{L e}\left(\frac{\partial C}{\partial x}+\frac{\partial T}{\partial x}\right)\right) d z=0 .
$$

This latter assumption leads to the following cubic equation giving $m$ as function of the dimensionless parameters: Pe, Ra, Le and $\psi$.

$$
m^{3}+\frac{108 P e}{R a \psi} m^{2}+\left(\frac{3456 P e^{2}}{R a^{2} \psi^{2}}+\frac{362880}{L e^{2} R a^{2} \psi^{2}}-\frac{504}{L e R a \psi}\right) m-\frac{30240 P e}{L e R a^{2} \psi^{2}}=0
$$

Under the condition that both the Lewis number, Rayleigh numbers and the separation ratio are positive, equation (28) with real coefficients admits three solutions. Depending on their corresponding discriminant $\Delta$, a cubic equation has three distinct real roots if $\Delta>0$, one real root and two non-real complex conjugate roots if $\Delta<0$. For $\Delta=0$, a cubic equation has multiple real roots. The discriminant $\Delta$ of equation (28) was obtained using the Maple algebra code. Its expression, which is a function of Le, $\mathrm{Pe}, \mathrm{Ra}$, and $\psi$, is long and complicated. For this reason it was not detailed here.

Case, $\Delta \geq 0$ The surface associated to $\Delta=0$ in the 3D space (Le, LePe, Ra $\psi$ ) separates the space into two regions, one corresponding to three real roots and the other one to one real and two complex conjugate roots. The surface associated to the case with three real roots, two of which are opposite, is close to the surface associated to the case $\Delta=0$. Its expression is given by: 7 RaLe $\psi-108 \mathrm{Le}^{2} \mathrm{Pe}^{2}-1134=0$. The value of the Rayleigh number and the corresponding real roots of the equation (28):

$$
\operatorname{Ra}=\frac{108}{7}\left(\frac{\mathrm{Le}^{2} \mathrm{Pe}^{2}+105}{\mathrm{Le} \psi}\right)
$$

and the three real roots are:

$$
\begin{gathered}
\mathrm{m}_{1}=-\frac{108 \mathrm{Pe}}{\mathrm{Ra} \psi} \\
\mathrm{m}_{2,3}= \pm 6 \sqrt{-\frac{10080}{\mathrm{Le}^{2} \mathrm{Ra}^{2} \psi^{2}}+\frac{14}{\mathrm{LeRa} \psi}-\frac{96 \mathrm{Pe}^{2}}{\mathrm{Ra}^{2} \psi^{2}}}
\end{gathered}
$$


Equation (29) shows that for a positive value of $\psi$ the Rayleigh number is always positive $R a>0$, which correspond to the case where the cellule is heated from below.

We deduce from equations (29) and (30), the maximum value of the species separation per unit length, $\mathrm{m}_{1}=-\frac{\sqrt{105}}{30}$ obtained for $P e_{o p t}= \pm \frac{\sqrt{105}}{L e}$. On the other hand, the maximal value of species separation $m_{2,3}= \pm \frac{\sqrt{14}}{9}$ obtained for $P e=0$, can be deduced from equations (29) and (31).

The evolution of the three roots of equation (29) is plotted, in Fig. 2, as a function of the Péclet number for $L e=230, \quad \psi=0.2$. The two symmetrical curves represent the separation obtained using equation (31) (the convection goes clockwise or counter-clockwise); while the solid line show the separation obtained using equation (30). In this latter case, $P e=0$, there is no species separation independently of the value of $R a$. The species separation is only possible for a horizontal cell heated from below ( $\operatorname{Ra}>0)$.

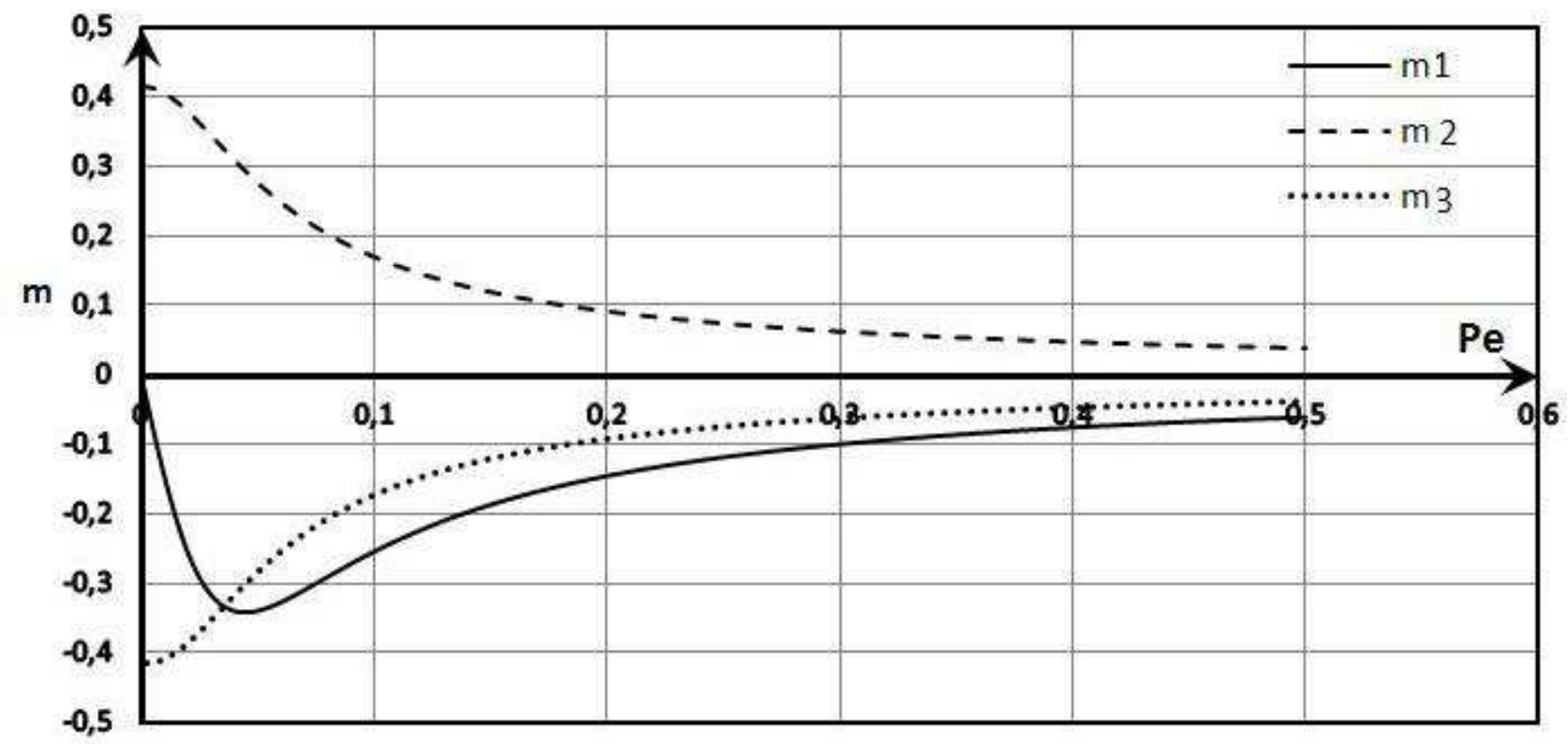

Figure 2. Separation as function of Péclet number, for $L e=230, \psi=0.2$

Case $\Delta<0$ The equation (28) has one real root and two non-real complex conjugate roots defined as a function of $\mathrm{Le}, \mathrm{Ra}, \mathrm{Pe}$ and $\psi$.

Here the maximum value of $m$, root of equation (28) is obtained for an optimum value of the Péclet number defined as follows:

$$
P e_{\text {opt }}=\frac{1}{30} \frac{\sqrt{-207900-105 L e R a \psi+70 \sqrt{6 L e^{2} R a^{2} \psi^{2}-3240 L e R a \psi+18662400}}}{L e}
$$

When the Péclet number is replaced, in the expression of $\mathrm{m}$, by its expression given in equation (32), $\mathrm{m}$ is obtained as a function of Le, $\psi$ and $\mathrm{Ra}$. The maximum of $\mathrm{m}$ as a function of $\mathrm{Ra}$ can then be calculated. For a cavity heated from below $m_{\max }=\frac{\sqrt{42}}{15}$ is obtained for $P e=\frac{\sqrt{42}}{L e}$ and $R a=\frac{540}{L e \psi}$. 
$m$ as function of the Rayleigh number can be seen in figure 3 for the cases $P e=0, P e=0.06, P e=$ 0.1 , where $L e=230, \psi=0.2$. The solid line represents the case where no velocity is applied on the upper wall (i.e $\mathrm{Pe}=0$ ). For $L e=230, \psi=0.2$, the species separation is only possible when the cell is heated from below and when the Rayleigh number exceeds a critical value $R a>R a_{c}$. A separation maximum is observed for an optimum value of Rayleigh number, where optimum coupling between convection and thermodiffusion is achieved. When the Rayleigh number is lower than the optimum value, the thermo-diffusion is predominant. In this case the separation, due mainly to the thermodiffusion, is small. Conversely, $R a>R a_{\text {opt }}$ the convection regime increases and tends to destroy the species segmentation. As a result, the separation decrease.

The two dotted curves represent the case where a constant velocity is applied on the upper wall $(P e=0.06, P e=0.1)$. For this case $(P e \neq 0)$ the separation is always possible whether the layer is heated from above or from below. This can be explained by the fact that the temperature gradient induces thermo-diffusion between the cold and the hot wall and the applied velocity leads to species separation between the two ends of the horizontal cell.

For $P e=0.06$ and $P e=0.1$ the maximum value of $m$ is respectively $m=0.417$ and $m=0.372$ obtained respectively for $R a=-9$ and $R a=-34$ (heated from above). For $P e=0$ the maximum horizontal transport rate $(m=0.42)$ is obtained for $R a=28.5$ (heated from below). In this case, the unicellular flow is possible if $\mathrm{Ra} \geq \frac{720}{\psi \mathrm{Le}}$. This configuration ( $\mathrm{Pe}=0$ ) was studied by Knobloch (1986). He found that the pure double diffusive convection flow transits to unicellular flow for a critical Rayleigh number $\mathrm{Ra}_{\mathrm{c}}=\frac{720}{\psi \mathrm{Le}}$.

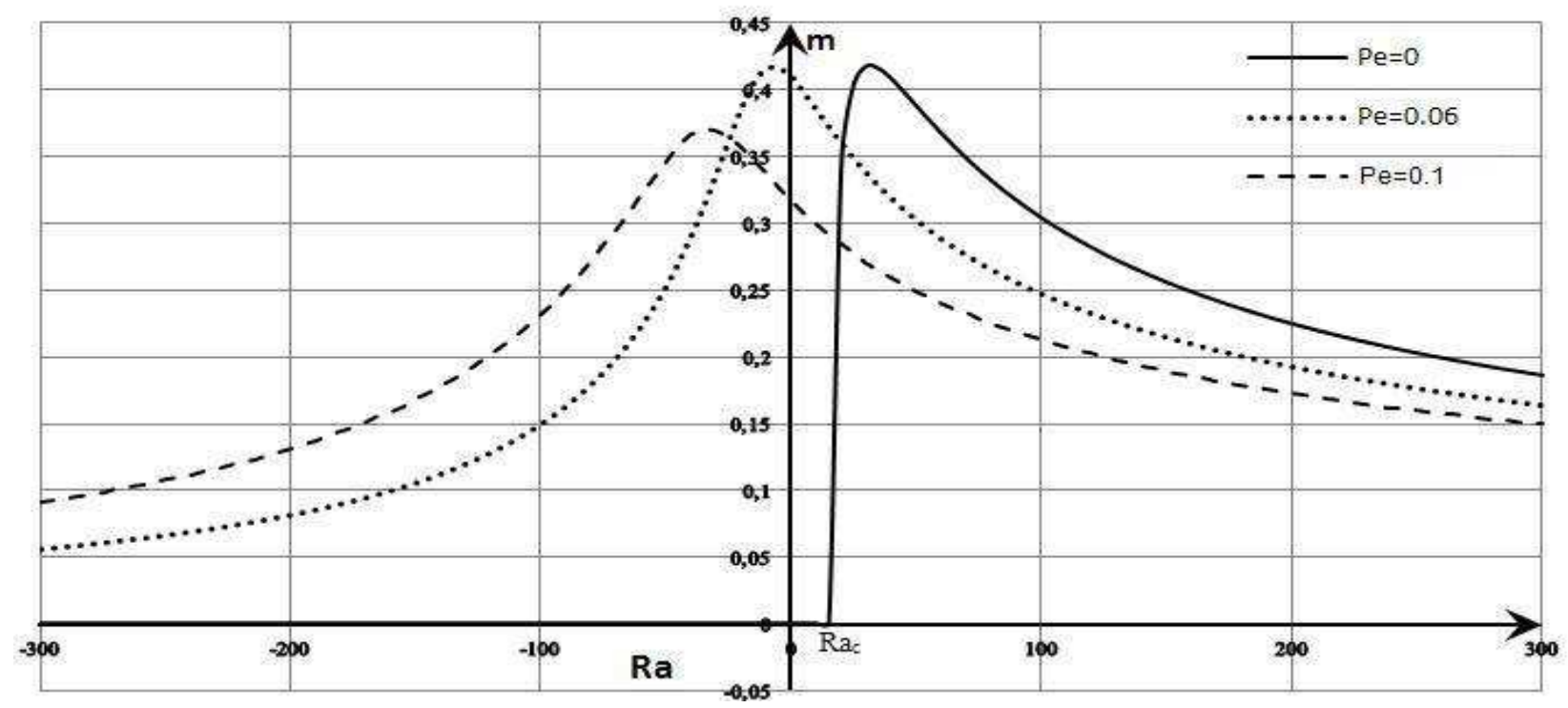

Figure 3. Species separation $\mathrm{m}$, versus Rayleigh number for $P e=0, P e=0.06, P e=0.1$ with $L e=230, \psi=0.2$.

\section{NUMERICAL METHOD}

Numerical simulations were carried out to evaluate the analytical results. For this purpose, the numerical solution of the full governing equations (10-13) with the associated boundary conditions 
(14-17), and with different initial values of $V, C, T$, was obtained using a finite element method (Comsol Multiphysics).

The mesh choice should only be viewed as a compromise between the convergence and solver memory requirements (UMFPACK direct solver was used for the simulation). A 4000 elements quadratic mesh (69986 degrees of freedom), which is more convenient for our rectangular cell problem, was used. As the analytical solution is valid for large aspect ratios, $\mathrm{A} \geq 10$ was used for all numerical simulations.

The analytical model is found to be in good agreement with the numerical results obtained by solving the complete system of governing equations.

A comparison of species separation m versus Péclet number Pe obtained, numerically and analytically, for a cell heated from below, $R a=15, L e=230, \psi=0.2, A=10$ is presented in figure 4. The analytical solution is represented with solid lines and the numerical values are represented with dots. The analytical solution is in good agreement with the numerical results.

When Péclet number is small or large (i.e. the applied velocity is low or high), the ratio between the mass diffusion time and the convective time does not allow the maximum species separation. The maximum value of the species separation is $m=0.432$ obtained for $\mathrm{Pe}=0.02$.

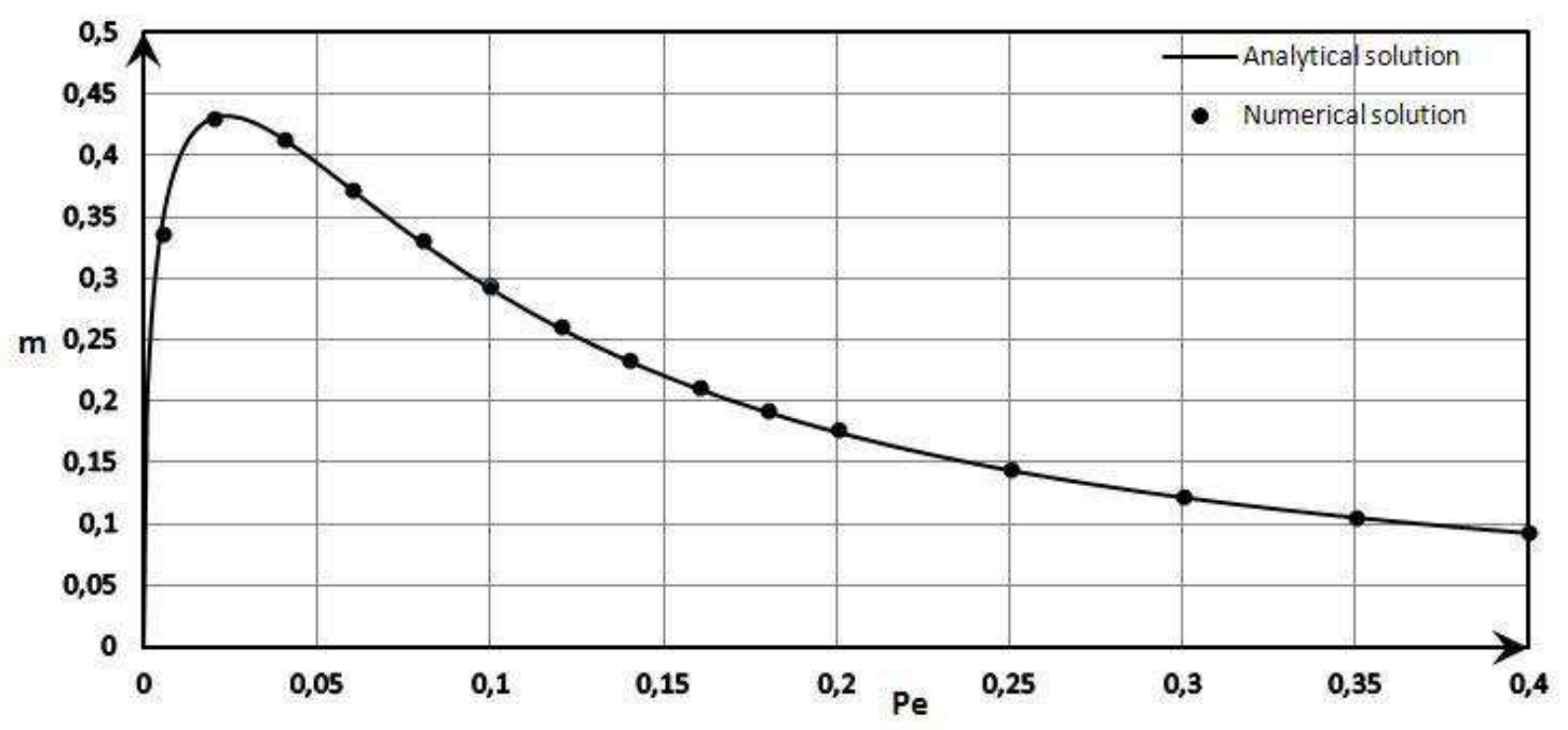

Figure 4. Variation of species separation $m$ versus Péclet number $(P e)$, with $R a=15$,

$$
L e=230, \psi=0.2, A=10 \text {. }
$$

The analytical and numerical results obtained for the species separation per unit length, $\mathrm{m}$, function of Pe are presented in table I, for $\operatorname{Pr}=27, R a=15, L e=230, \psi=0.2, A=10$. 
Table I. Comparison between analytical an numerical values of $\mathrm{m}$ results for $\operatorname{Pr}=27, \psi=0.1, L e=230, R a=15$.

\begin{tabular}{ccc}
\hline \hline$P e$ & $m_{\text {Ana }}$ & $m_{\text {Num }}$ \\
\hline 0.02 & 0.429 & 0.43 \\
0.04 & 0.413 & 0.414 \\
0.06 & 0.372 & 0.373 \\
0.08 & 0.329 & 0.330 \\
0.1 & 0.2917 & 0.293 \\
0.12 & 0.2596 & 0.2613 \\
0.14 & 0.2327 & 0.2343 \\
0.16 & 0.2102 & 0.2116 \\
0.18 & 0.1912 & 0.1925 \\
0.2 & 0.1751 & 0.1765 \\
0.25 & 0.1440 & 0.1450 \\
0.3 & 0.1219 & 0.1226 \\
0.4 & 0.0930 & 0.098
\end{tabular}

Figure 5. represents the variation of the concentration field of a binary fluid mixture for different values of the Péclet number $P e$, for $R a=15, \operatorname{Pr}=10, L e=230, \psi=0.2$ and $A=10$. The black lines correspond to the iso-concentrations while the color scales represents the mass fraction intensity of the heaviest species. When $P e$ number increases, i.e. the flow velocity increases, the isoconcentration curvature increases and the separation decreases

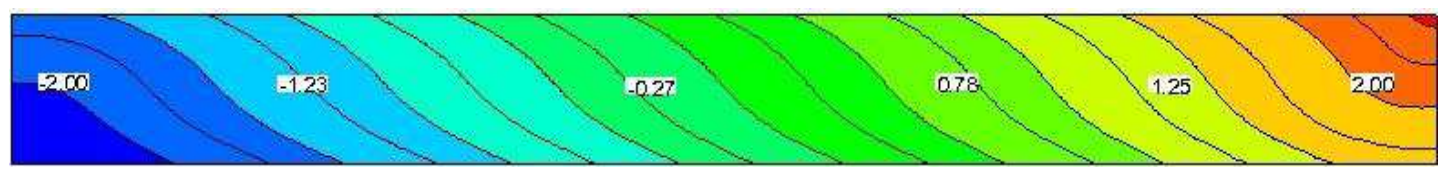

(a)

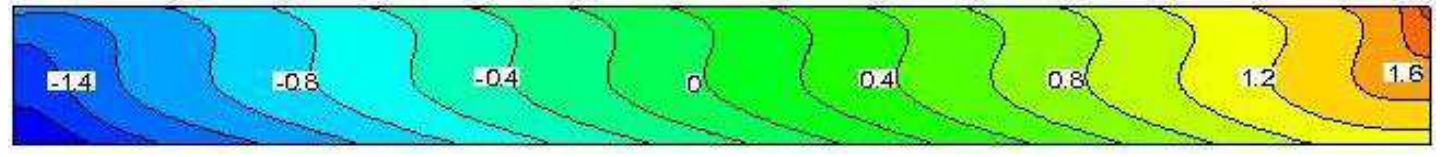

(b)

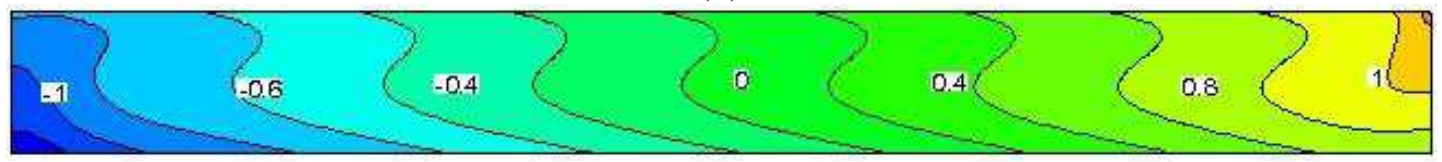

(c)

Figure 5. Iso-concentration lines and variation of the concentration field as a function of Péclet number $P e$ (a) $P e=0.02$, (b) $P e=0.1$, (c) $P e=0.18$ with $R a=15$, and $L e=230, \psi=0.2, A=10$ $\operatorname{Pr}=27$.

For a cell heated from above, we present in figure 6 an analytical and numerical comparison giving the value of $\mathrm{m}$ as a function of Péclet number for $R a=-50, L e=230, \psi=0.2$. The analytical solution is represented by solid lines and numerical values are symbolically represented by dots. The analytical solution is in good agreement with the numerical results. For $P e=0.115$ we obtain the maximum value of $m: m=0.36$. 


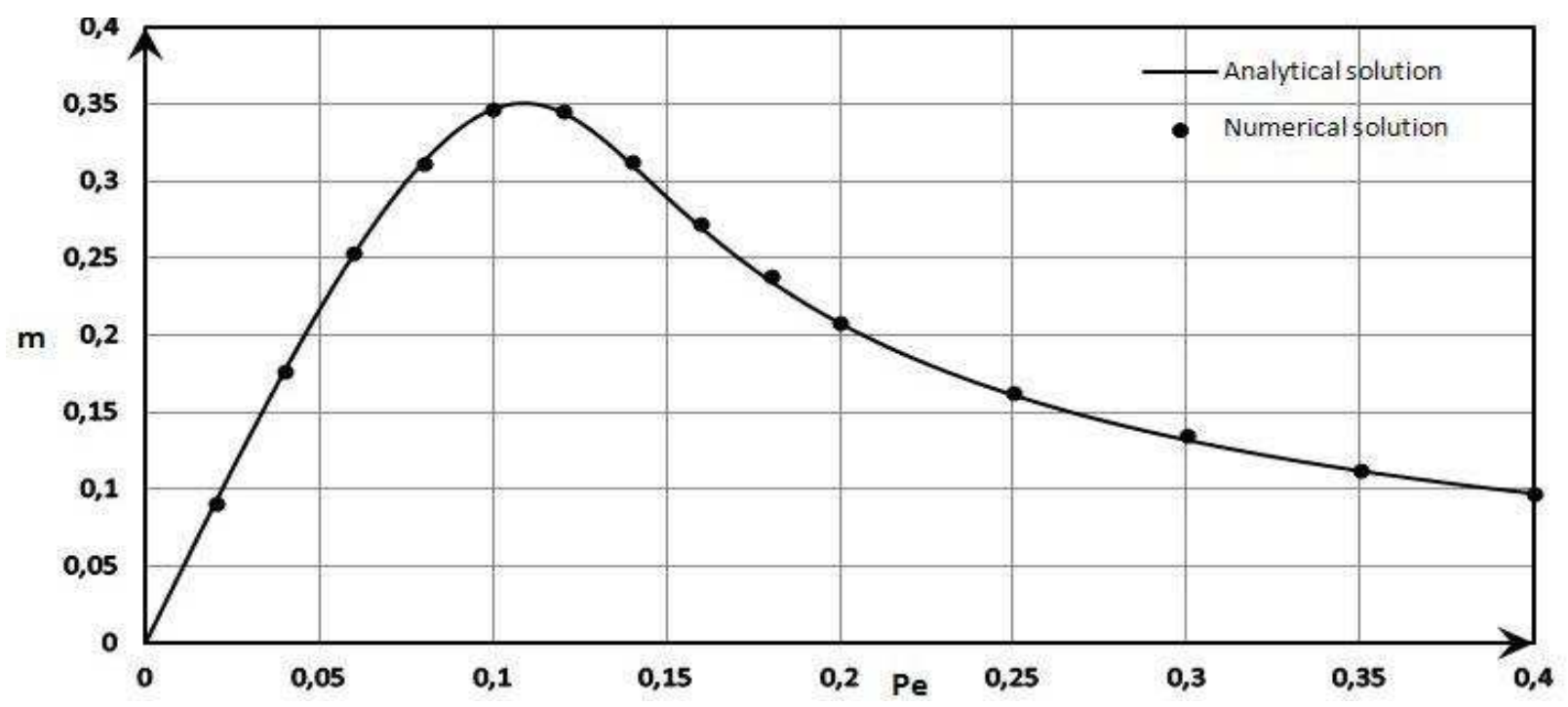

Figure 6. Variation of separation $m$ versus Péclet number $P e$, for $R a=-50$,

$$
L e=230, \psi=0.2, A=10 \text {. }
$$

Figure 7. Shows the variation of the concentration field at different values of the Péclet numbers $P e=0.02, P e=0.1, P e=0.18$ for $R a=-50, \operatorname{Pr}=10, L e=230, \psi=0.2, A=10$. The lines correspond to the isoconcentration, while color represents the intensity of the mass fraction of the heaviest species.

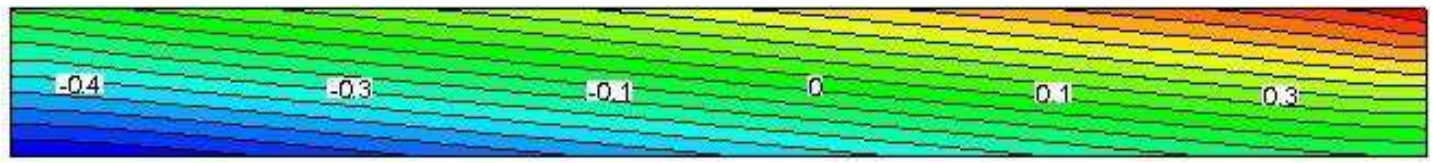

(a)

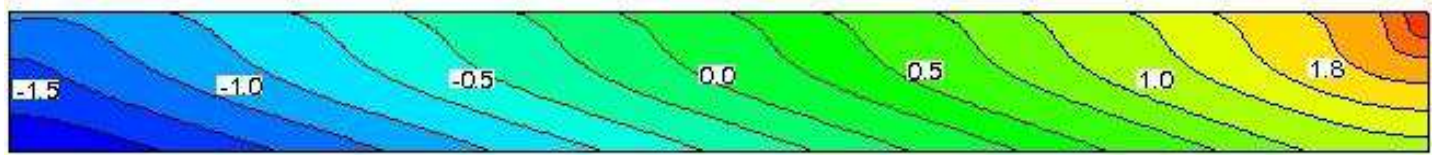

(b)

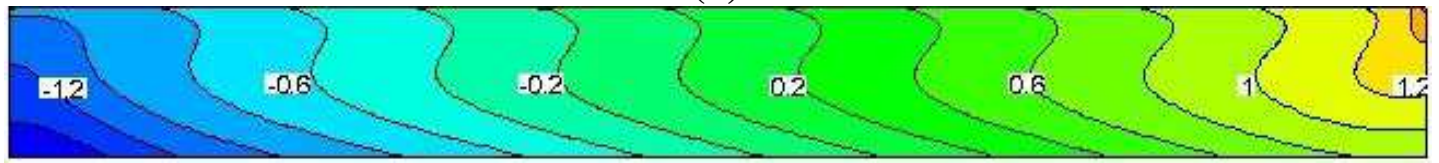

(c)

Figure 7. Iso-concentration lines and variation of the concentration field versus Péclet number $P e$ (a) $P e=0.02$,(b) $P e=0.1$, (c) $P e=0.18$ with $R a=-50$, and $L e=230, \psi=0.2, A=10 \operatorname{Pr}=27$.

Velocity profile The structure of the flow inside the cavity and the associated velocity's profile induced by the top wall driven by constant velocity along the $\mathrm{x}$ axis depends on the direction of convective rotating vortex generated by free convection inside the horizontal cell.

The equation of the velocity profile obtained in equation (25) can be also written the form:

$u=\frac{1}{12} z\left[\left(-2 z^{2}+3 z\right) R a \psi m+(36 z-24) P e\right]$

We verify that the discriminant of the quadratic equation associated to the velocity is positive for all values of $\mathrm{Ra}, \mathrm{Pe}$ and $\Psi$. Then there are two distinct real roots. If these two roots are in the interval $[0,1]$ the velocity is equal zero at two points inside the cross section of the cell. We show that both 
roots are localised in the interval [0,1] only when the value of $X=\frac{P e}{R a \psi m}$ is in the range of [$0.042,0]$.

The velocity profile in the cavity for $R a=60, P e=0.06, L e=100, \psi=0.1, A=10$ and $\mathrm{m}=0.4319$ leads to $X=0.231 \notin[0.042,0]$ it follows then that the profile velocity has only one value of $z \in[0,1]$ for which the velocity equal zero. The correspondent profile velocity is presented in Figure 8 . In figure 9 , we present the associated stream function obtained numerically for cell with aspect ratio $A=10$.

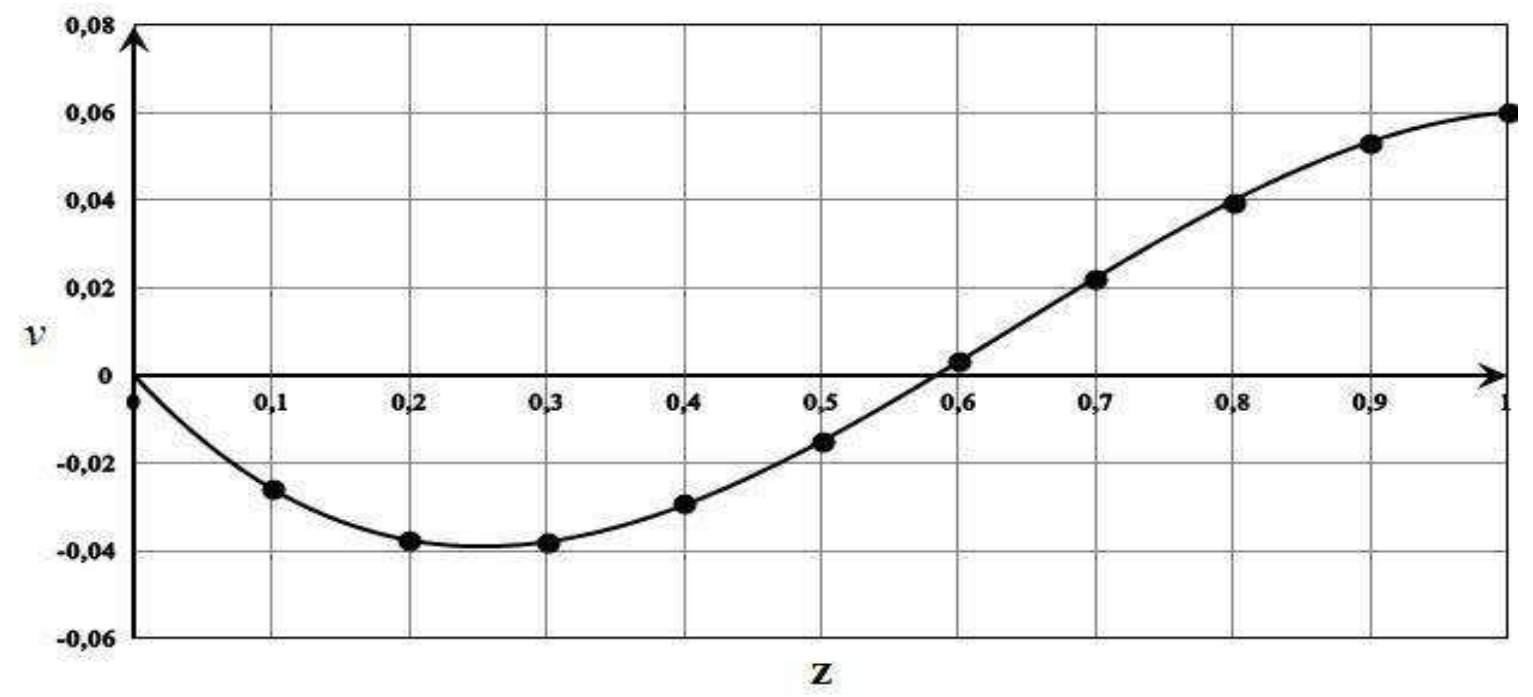

Figure 8. Profile of velocity for $R a=60, P e=0.06, \psi=0.1, L e=100$.

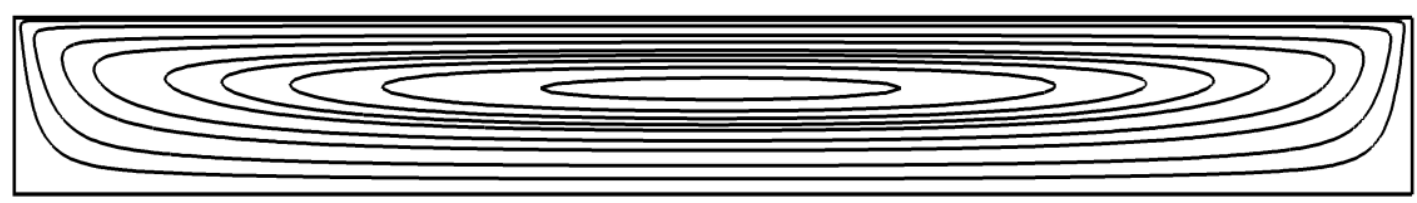

Figure 9. Streamlines for $R a=60, P e=0.06, \psi=0.1, L e=100$

for $R a=200, L e=100, \psi=0.1, P e=0.05, m=-0.1463$ the value of $X=-0.171$ is in the range of ] $-0.042,0$ [ and the velocity is equal zero for two values of $\mathrm{z}\left(\mathrm{z}_{1}=0.33, \mathrm{z}_{2}=0.84 \in\right] 0,1$ [ $)$ the figure 10 shows the corresponding profile velocity. Figure 11. presents the associated streamlines showing two counter-rotating superposed cells. 


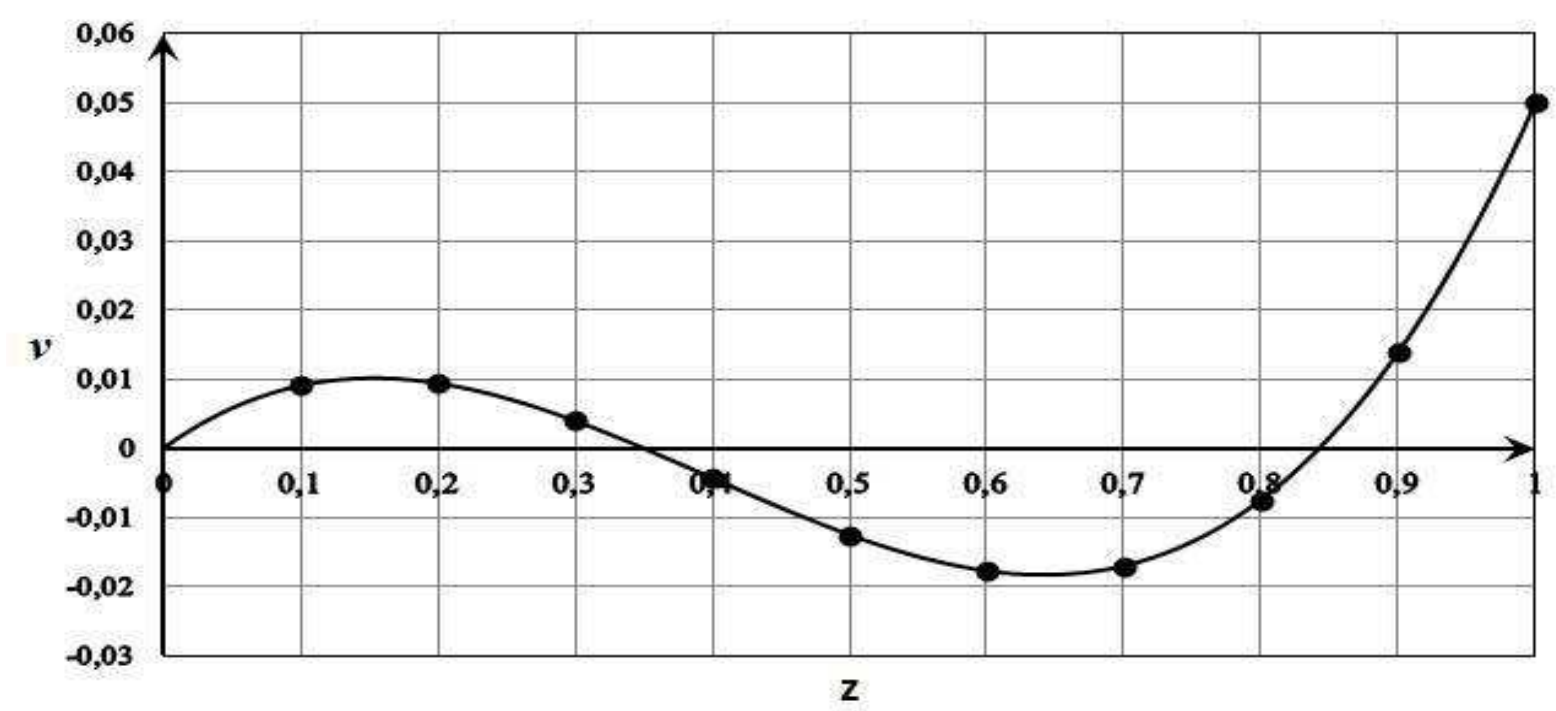

Figure 10. Profile of velocity for $L e=100, R a=200 P e=0.05, m=-0.1463 \psi=0.1$.

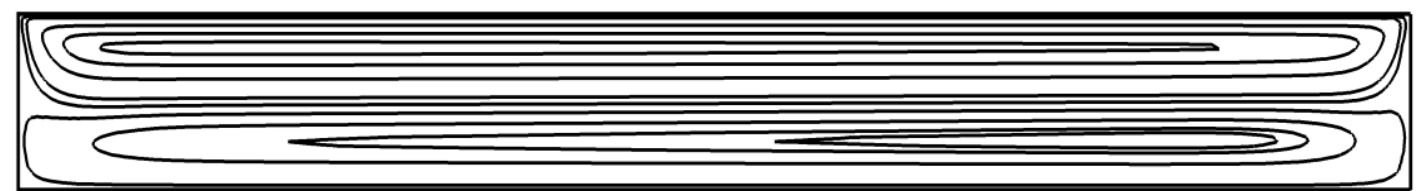

Figure 11. Streamlines for $L e=100, R a=200, P e=0.05, m=-0.1463 \psi=0.1$.

\section{CONCLUSION}

In this study, a new procedure leading to species separation in a horizontal rectangular cavity, filled with a binary fluid, heated from above or from below, was presented. A constant horizontal velocity was applied on the upper horizontal wall. The two control parameters of this procedure were: the applied velocity on the upper wall which determines the intensity of the convective flow, and the temperature difference between the two horizontal plates which controls the intensity of the thermodiffusion. In this study the species separation was quantified by both analytical and numerical methods. The influence of the thermal Rayleigh number and the Péclet number for different values of Prandlt, Lewis numbers and separation ratio was quantified and discussed. The optimum species separation was obtained for a cell heated from below or from above. The analytical and numerical results obtained were in good agreement.

\section{REFERENCES}

Alloui, Z., Dufau, L., Beji, H. and Vasseur, P. (2009) 'Multiple steady states in a porous enclosure partially heated and fully salted from below', International Journal of Thermal Sciences, 48(3), 521534.

Bennacer, R., Mahidjiba, A., Vasseur, P., Beji, H. and Duval, R. [2003] 'The Soret effect on convection in a horizontal porous domain under cross temperature and concentration gradients', International Journal of Numerical Methods for Heat \& Fluid Flow, 13(2-3), 199-215.

Bennacer, R., Mohamad, A. A. and El Ganaoui, M. [2009] 'Thermodiffusion in porous media: Multidomain constitutant separation', International Journal of Heat and Mass Transfer, 52(7-8), 1725-1733. 
Bou-Ali, M. M., Ecenarro, O., Madariaga, J. A., Santamaria, C. M. and Valencia, J. J. [1999] 'Stability of convection in a vertical binary fluid layer with an adverse density gradient', Physical Review E, $59(1), 1250-1252$.

Charrier-Mojtabi M C, Elhajjar B and Mojtabi A [2007] Analytical and numerical stability analysis of Soret-driven convection in a horizontal porous layer Phys. Fluids 19, 1241,04.

Clusius, K. and Dickel, G. [1938] 'New Process for Separation of Gas Mixtures and Isotopes', Naturwissenschaften, 26, 33.

Elhajjar, B., Charrier-Mojtabi, M. C. and Mojtabi, A. [2008] 'Separation of a binary fluid mixture in a porous horizontal cavity', Physical Review E, 77(2), 6.

Elhajjar, B., Mojtabi, A. and Charrier-Mojtab, M. C. [2009] 'Influence of vertical vibrations on the separation of a binary mixture in a horizontal porous layer heated from below', International Journal of Heat and Mass Transfer, 52(1-2), 165-172.

Elhajjar, B., Mojtabi, A., Costeseque, P. and Charrier-Mojtabi, M. C. [2010] 'Separation in an inclined porous thermogravitational cell', International Journal of Heat and Mass Transfer, 53(21-22), 48444851.

Elhajjar, B., Mojtabi, A., Marcoux, M. and Charrier-Mojtabi, M. C. [2006] 'Study of thermogravitation in a horizontal fluid layer', Comptes Rendus Mecanique, 334(10), 621-627.

Furry W.H., Jones R.C. and Onsager L.[ 1939], ' On theory of isotope separation by thermal diffusion, Phy. Rev.55, 1083-1095.

Knobloch E and Moore D R [1988] Linear stability of experimental Soret convection. Phys. Rev. A 37 860-870

Platten, J. K., Bou-Ali, M. M. and Dutrieux, J. F. [2003] 'Enhanced molecular separation in inclined thermogravitational columns', Journal of Physical Chemistry B, 107(42), 11763-11767.

Shevtsova, V. M., Melnikov, D. E. and Legros, J. C. [2006] 'Onset of convection in Soret-driven instability', Phys Rev E Stat Nonlin Soft Matter Phys, 73(4 Pt 2), 047302.

Zebib A.; Bou-Ali M.M.,[2009] Inclined layer Soret Instabilities, Phys. Rev. E 79, 056305, 1-6. 